\title{
Immunodeficient Mouse
}

National Cancer Institute

\section{Source}

National Cancer Institute. Immunodeficient Mouse. NCI Thesaurus. Code C15156.

Any mouse strain with a faulty immune system such that its ability to fight infectious disease is compromised or ablated. Immunodeficient mice may be derived by inbreeding or genetic engineering. Immunodeficiency may also be induced by some chemicals, heavy metals, alkylating agents, radiation, and thymectomy. 